\title{
Association of tympanostomy tubes with future assistive hearing devices-a population based study
}

\author{
Jason A. Beyea ${ }^{1,2^{*}}$ (D), Bonnie Cooke ${ }^{3}$, Emily Rosen ${ }^{3}$ and Paul Nguyen ${ }^{2}$
}

\begin{abstract}
Background: Ear (tympanostomy) tube (TT) placement is a common ambulatory surgery in children. Despite the commonality of this treatment, the long-term effects are unknown. The objective of this study was to determine the rate of permanent hearing loss, as measured by use of a rehabilitative hearing device.

Methods: A retrospective comprehensive population-based cohort study was performed, evaluating all hospitals in the Canadian province of Ontario. Three cohorts of children were constructed: $\Pi$ - at least one ear tube procedure ( $n=193,880)$, No-TT -recurrent visits to a physician for middle ear disease, did not undergo ear tubes $(n=203,283)$, and Control - an age/sex matched group who had not undergone ear tubes and who didn't have repeat physician visits for middle ear disease $(n=961,168)$. The main outcome measures were risk and odds ratio (OR) of rehabilitative hearing devices.

Results: The $\Pi$ cohort had a higher risk of obtaining a hearing aid (OR 4.53 vs. No- $T, p<0.001$; OR 10.81 vs. Control, $p<0.001$ ), an FM system (OR 3.84 vs. No-T, $p<0.001$; OR 15.13 vs. Control, $p<0.001$ ), and an implanted bone conduction device (OR 5.08 vs. No-T, $p<0.001$; OR 15.67 vs. Control, $p<0.001$ ).

Conclusions: An association between ear tube placement and long-term need for a rehabilitative hearing device was found. This association warrants future prospective research in this area.

Keywords: Hearing loss, Tympanostomy tubes, Hearing aids, Otitis media, Ear surgery, Outcomes, Implantable hearing devices
\end{abstract}

\section{Background}

Ear (tympanostomy) tube (TT) placement is a common ambulatory surgery that children undergo [1]. Persistent otitis media with effusion (OME) and recurrent acute otitis media (AOM) are the most common indications for which TT placement is performed [2].

Insertion of TT has been shown to be associated with development of eardrum pathologic abnormalities, including segmental atrophy, perforation, and cholesteatoma [3]. Furthermore, studies exist supporting higher hearing thresholds in children managed with TT insertion versus those managed conservatively/medically $[4,5]$. However,

\footnotetext{
*Correspondence: jason.beyea@queensu.ca

'Department of Otolaryngology, Kingston Health Sciences Centre, Queen's University, Kingston, 144 Brock Street, Kingston, Ontario K7L 5G2, Canada ${ }^{2}$ ICES Adjunct Scientist ICES Queen's, Queen's University School of Medicine, Kingston, 144 Brock Street, Kingston, Ontario K7L 5G2, Canada

Full list of author information is available at the end of the article
}

others have not found evidence of hearing loss post-TT insertion $[6,7]$.

The consistent feature of these studies is the small sample size, and as such, the risk of type-2 error is present. The current study was designed to evaluate in a large comprehensive population long-term hearing loss in TT patients of a severity that merited a rehabilitative hearing device, and to compare this population to patients with recurrent middle ear disease managed without TT, and to healthy age/sex-matched controls.

\section{Methods}

\section{Ethical considerations}

Queen's University Health Sciences \& Affiliated Teaching Hospitals Research Ethics Board approved this study, project \#6017300. 


\section{Participants}

Ontario has a population of over 14 million residents, the largest Canadian province. Canadian hospitals must report all same-day and inpatient operative procedures. The Canada Health Act governs the Canadian healthcare system, which is a publically funded and administered. This Act mandates comprehensive universal coverage for all medically necessary services, including TT and bone-conducting hearing aids. Private health insurance for these procedures is prohibited. Furthermore, all residents are eligible (based on medical necessity) for partial financial coverage of assistive hearing devices (such as hearing aids and FM systems) through the Assistive Devices Program (ADP). These surgical procedures and assistive devices are available to all persons equally. The present study defined children as persons aged 0 to 18 years. Exclusion criteria were: a valid patient identifier was not available in the dataset, if age/sex information was not available, or if they had undergone a TT procedure (Ontario Health Insurance Plan feecode Z914) in the 2 years prior to January 1, 1994. To further characterize the cohorts, the diagnosis of cleft palate/lip was sought (Table 1), using a window of 2 years prior to the index date and 5 years following the index date.

\section{Data sources and data linkage}

The data for this study was obtained from administrative datasets housed at ICES. ICES is an independent, nonprofit research organization funded by the Ontario Ministry of Health and Long Term Care whose comprehensive data holdings include all health care related events for the population of Ontario. The Registered Persons Database (RPDB) contains demographic information for all Ontario residents who are eligible for the Ontario Health Insurance Plan (OHIP). RPDB data is maintained by the Ontario Ministry of Health and Long Term Care. RPDB data includes: health card number, date of birth, gender, address, and deceased date (if applicable). At ICES, all personal identifying information

Table 1 Ontario Health Insurance Plan (OHIP) Diagnosis and Billing Administrative Codes

\begin{tabular}{lll}
\hline & $\begin{array}{l}\text { Diagnosis } \\
\text { Code }\end{array}$ & $\begin{array}{l}\text { Billing } \\
\text { Code }\end{array}$ \\
\hline $\begin{array}{l}\text { Eustachian Tube Dysfunction/Serous Otitis } \\
\text { Media }\end{array}$ & 381 & \\
$\begin{array}{l}\text { Eustachian Tube Dysfunction/Suppurative } \\
\text { Otitis Media }\end{array}$ & 382 & \\
$\begin{array}{l}\text { Cleft Palate/Lip } \\
\text { Myringotomy with insertion of ventilating } \\
\text { (tympanostomy) tube }\end{array}$ & 789 & Z914 \\
$\begin{array}{l}\text { Implantable bone conduction hearing } \\
\text { aid insertion }\end{array}$ & & E346 \\
\hline
\end{tabular}

in RPDB is removed. An anonymous unique identifier, the ICES Key Number (IKN) is generated from each health number. The IKN is used to link data sources within ICES. Diagnosis and fee-for-service claims submitted by physicians, and paid by the universal health care system, are contained within the OHIP database. The Assistive Devices Program (ADP) database contains (among many other variables) information regarding attainment of an assistive hearing device, including a hearing aid and/or FM system.

\section{Intervention}

Three cohorts were constructed and evaluated at ICES. The TT cohort was constructed of all children who had received at least one TT surgery during the study period (January 1, 1994 to October 31, 2013). The No-TT cohort had more than five visits to a physician with an Eustachian tube dysfunction diagnosis (Serous Otitis Media or Suppurative Otitis Media) within 1 year (Table 1). These No-TT cohort patients did not undergo TT surgery, and all children who met this criterion were included in this cohort. The purpose of this criterion was to capture children with considerable ongoing middle ear dysfunction, while avoiding capture of children with occasional middle ear disease. The Eustachian tube dysfunction diagnostic codes (Table 1) were validated in the TT cohort - based on an average of five visits in the year prior to TT placement. There is also construct validity, since based on current indications for TT surgery [8], many children with five or more visits per year to primary care for AOM or middle ear disease would be considered for TT surgery. A Control cohort was created, by matching to the TT cohort 5-to-1 by birth year and sex, Ontario children who had two or less uses of these Eustachian tube dysfunction diagnostic codes in any 1 year period. In clinical practice, these are children who it would be very unlikely that TT surgery would be presented as a management option. In the year prior to the TT surgery in the TT cohort, less than $30 \%$ of patients had these codes used 2 or less times. Patients were also excluded from the No-TT and Control cohorts if they had undergone a TT surgery between January 1992 and March 2016. The creation of these three cohorts permitted determination of risks of assistive hearing devices in patients who underwent TT surgery, patients with recurrent middle ear disease managed non-surgically, and controls.

\section{Outcomes}

In the three cohorts, OHIP diagnostic and billing codes for ear disease and ear surgical procedures performed (Table 1), and obtainment of an assistive hearing device from the ADP claims database, were collected and evaluated. 


\section{Statistical analysis}

Descriptive statistics of patient characteristics were obtained. Logistic regression analyses were then utilized to compare ear surgical procedures performed (i.e., boneconducting hearing aids) and obtainment of an assistive hearing device (i.e., unilateral/bilateral hearing aids and FM system) claimed in patients between the TT cohort and the No-TT cohort, and between the TT cohort and the Control cohort.

Statistical analyses were performed at ICES using SAS Enterprise Guide software, version 7.1 (SAS Institute, Cary, NC). Two-sided statistical significance was a $p$ value $<0.05$.

\section{Results}

Three cohorts of children were studied: TT cohort (193, 880 children), No-TT cohort (203,283 children), and Control cohort (961,168 children) (Table 2). Both the TT and No-TT cohort had an average above 5 episodes of physician-diagnosed Eustachian tube dysfunction in the year preceding the index date.

Occurrence and odds ratios of assistive hearing devices were compared in the three cohorts (Table 3). While overall occurrences were low, the large size of the cohorts permitted meaningful comparisons. Odds ratios comparing the TT cohort with the Control cohort were high for all assistive hearing devices. In addition, the odds ratios of the TT cohort versus the No-TT cohort were consistently around 4 for all assistive hearing devices.

Average time from index date to first hearing aid or FM system was found to be above 6 years in all three cohorts (Fig. 1). This analysis was performed only for patients who had an index date of April 1, 1999 or later, as earlier information was not available from the ADP database. Average time from index date to first

Table 2 Cohort Characteristics

\begin{tabular}{llll}
\hline & TT Cohort & $\begin{array}{l}\text { No-TT } \\
\text { Cohort }\end{array}$ & $\begin{array}{l}\text { Control } \\
\text { Cohort }\end{array}$ \\
\hline Sample Size & 193,880 & 203,283 & 961,168 \\
$\begin{array}{l}\text { Age (years) at Index Date } \\
\text { (Mean } \pm \text { SD) }\end{array}$ & $3.61 \pm 2.85$ & $2.43 \pm 2.65^{*}$ & $3.08 \pm 2.88^{*}$ \\
$\begin{array}{l}\text { Sex (\% female) } \\
\begin{array}{l}\text { Episodes of Physician- } \\
\text { diagnosed Eustachian }\end{array}\end{array}$ & 39.29 & $45.21^{*}$ & 39.30 \\
$\begin{array}{l}\text { Tube Dysfunction } \\
\text { (Mean } \pm \text { SD, per year) }\end{array}$ & & $5.06 \pm 0.37^{\mathrm{b}^{*}}$ & $0.14 \pm 0.40^{\mathrm{b}^{*}}$ \\
\hline
\end{tabular}

andex dates are the date of first $\Pi$ procedure for the $\Pi T$ cohort, latest diagnosis date of $>5$ episodes in 1-year period for the No-T cohort, and date of first $\Pi$ procedure of the matched children from $\Pi \pi$ cohort for the Control cohort

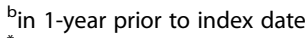

${ }^{*} p<0.001$ versus $\pi$ cohort

TT Tympanostomy Tube

SD Standard Deviation implanted hearing device (bone-conducting hearing aid) was above 5 years in all three cohorts (Fig. 2).

By cohort, risks of diagnosis of cleft palate/lip were $1.621 \%$ (TT cohort), $0.221 \%$ (No-TT cohort), and $0.072 \%$ (Control cohort). Evaluating the risks of cleft palate/lip in the subgroup of each cohort who obtained "Any Hearing Rehabilitative Device" revealed that only a minority of patients in each cohort who had a hearing device were patients with cleft palate/lip: 6.780\% (TT cohort), $2.088 \%$ (No-TT cohort), and 1.292\% (Control cohort).

\section{Discussion}

In a comprehensive dataset, this study reports the need for assistive hearing devices in ear tube patients, recurrent ear disease patients managed non-operatively, and healthy control patients. Furthermore, there is an association between TT and needing an assistive hearing device. This study is not able to comment on causation, and the authors believe causation should not be inferred.

Controversy exists regarding the role of TT in pediatric patients with recurrent/persistent middle ear disease. While studies support short term resolution of fluid and improvement of hearing in children with otitis media with effusion [9-11], and possibly reduction in episodes of AOM in children with recurrent acute otitis media [12-16], there is also a possibility that the tubes themselves contribute to the development of chronic ear disease and abnormalities of the eardrum [3, 17-19]. Prompt insertion of TT does not improve developmental outcomes in children with persistent otitis media with effusion [20, 21]. Furthermore, children with recurrent middle ear disease who undergo TT placement have higher future risk of advanced ear surgery, compared with those managed conservatively [22]. It is within the context of this controversy that the results of this study, which demonstrated an association between higher assistive hearing device usage in children who have undergone TT placement, are important to consider.

This study demonstrated higher odds ratios of rehabilitative hearing devices in the TT cohort, compared both to the No-TT and Control cohorts. The TT comparison to the Control provides information as to the risk on hearing of the combined effect of the underlying middle ear disease and a possible role of the tubes themselves. The results obtained in this respect are expected, as recurrent/persistent middle ear disease itself is known to be a risk factor for hearing loss [5]. Interestingly, when compared to a group matched for middle ear disease severity (No-TT cohort), there was still a notable increased risk of the need for rehabilitative hearing devices in the children who underwent ear tubes (TT cohort). This data reveals the association of ear tube placement with hearing loss in children with recurrent/ 
Table 3 Occurrence and Odds Ratio (OR) [with 95\% Confidence Interval (CI)] of Assistive Hearing Devices

\begin{tabular}{llllll}
\hline & $T$ Cohort (\%) & No-TT Cohort (\%) & Control Cohort (\%) & TT vs. No-TT [OR (95\% CI)] & TT vs. Control [OR (95\% Cl)] \\
\hline Implanted bone conduction device & 0.032 & 0.006 & 0.002 & $5.08(2.80-9.23)^{*}$ & $15.67(9.47-25.91)^{*}$ \\
Unilateral hearing aid & 0.341 & 0.081 & 0.025 & $4.21(3.55-5.00)^{*}$ & $13.74(11.85-15.94)^{*}$ \\
Bilateral hearing aid ${ }^{\text {a }}$ & 0.647 & 0.139 & 0.067 & $4.69(4.12-5.34)^{*}$ & $9.70(8.82-10.67)^{*}$ \\
Unilateral or bilateral hearing aid & 0.988 & 0.220 & 0.092 & $4.53(4.09-5.02)^{*}$ & $10.81(9.98-11.71)^{*}$ \\
FM system hearing device & 0.121 & 0.031 & 0.008 & $3.84(2.91-5.06)^{*}$ & $15.13(11.69-19.57)^{*}$ \\
Any hearing rehabilitation device & 1.035 & 0.236 & 0.097 & $4.43(4.01-4.89)^{*}$ & $10.76(9.95-11.63)^{*}$ \\
\hline
\end{tabular}

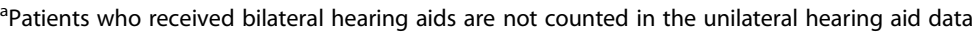
${ }^{*} p<0.001$

persistent middle ear disease. The authors caution that this does not prove causation, but the pattern obtained requires attention. These findings also agree with those obtained by Stenstrom et al. [5] Those authors randomized 113 children with recurrent otitis media with effusion to medical therapy or ear tube placement. They found those children who underwent tubes had hearing thresholds 2.1 to $8.1 \mathrm{~dB}$ higher, and much more frequent pathologic abnormalities of the eardum, compared to those treated medically. Similar audiometric and pathologic results were found in other small studies $[4,6,13,23]$. A large meta-analysis [24] demonstrated that ear tubes increased the long-term risk of eardrum scarring, focal atrophy, retraction, cyst formation (cholesteatoma), and perforation, compared to children not undergoing tubes. Furthermore, the risks were much higher if long-term tubes were used compared with short-term tubes. This last point is particularly interesting, as it further highlights the potential role the tube itself could play.

This study used an operational definition of disease severity. This was the number of presentations to a physician in one year in which the child received a diagnosis of middle ear disease. Both the TT and No-TT cohorts had greater than 5 visits in the year prior to the index date. There is no agreed upon measure of severity of Eustachian tube dysfunction or middle ear disease. The authors believe that within the limitations of administrative data, this measure is the most appropriate and objective measure to match the groups.

A possible explanation for the average 6 year delay (after the index date) in obtaining amplification is that children with mild/moderate hearing loss may not be identified until significant speech and language delays are recognized in school. In Ontario, it is common for children with permanent hearing impairment to be

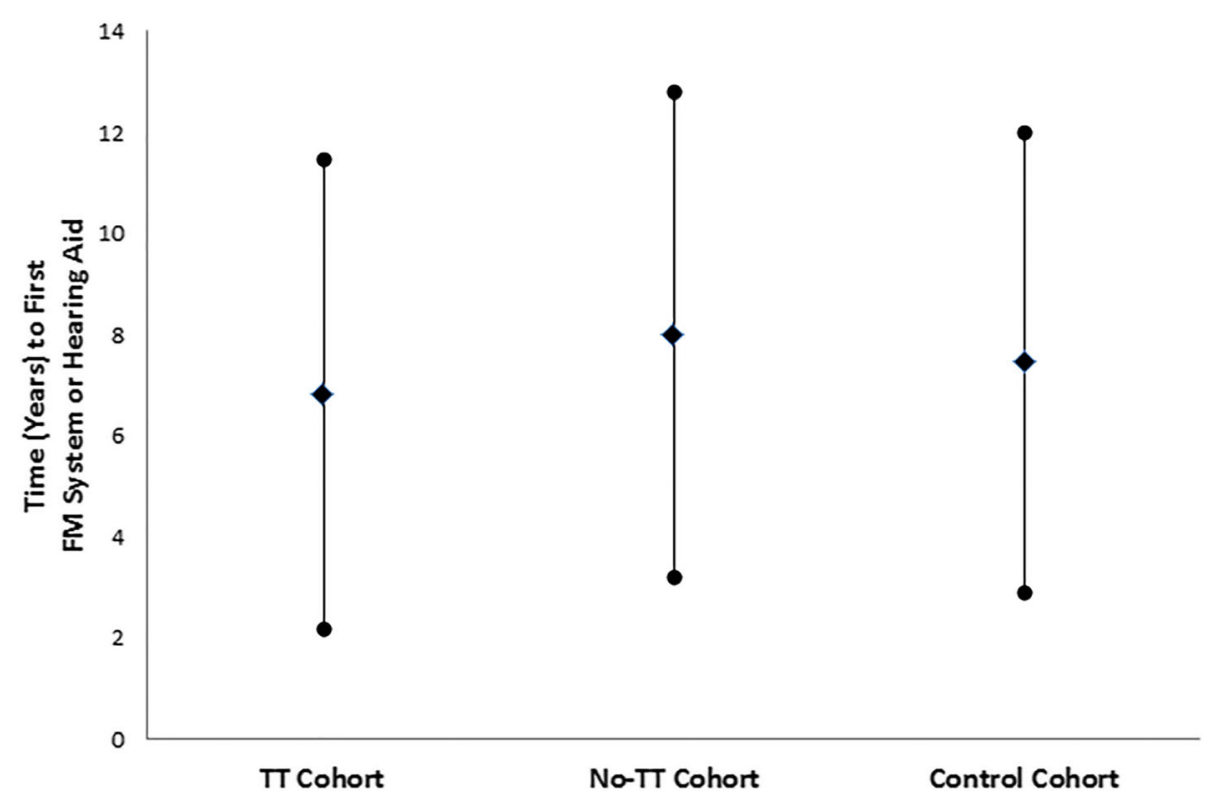

Fig. 1 Time (years) (Mean \pm SD) from index date to first FM system or hearing aid in the three cohorts. Time was created for cohort patients whose index date was after April 1, 1999 due to data limitations in the ADP database 


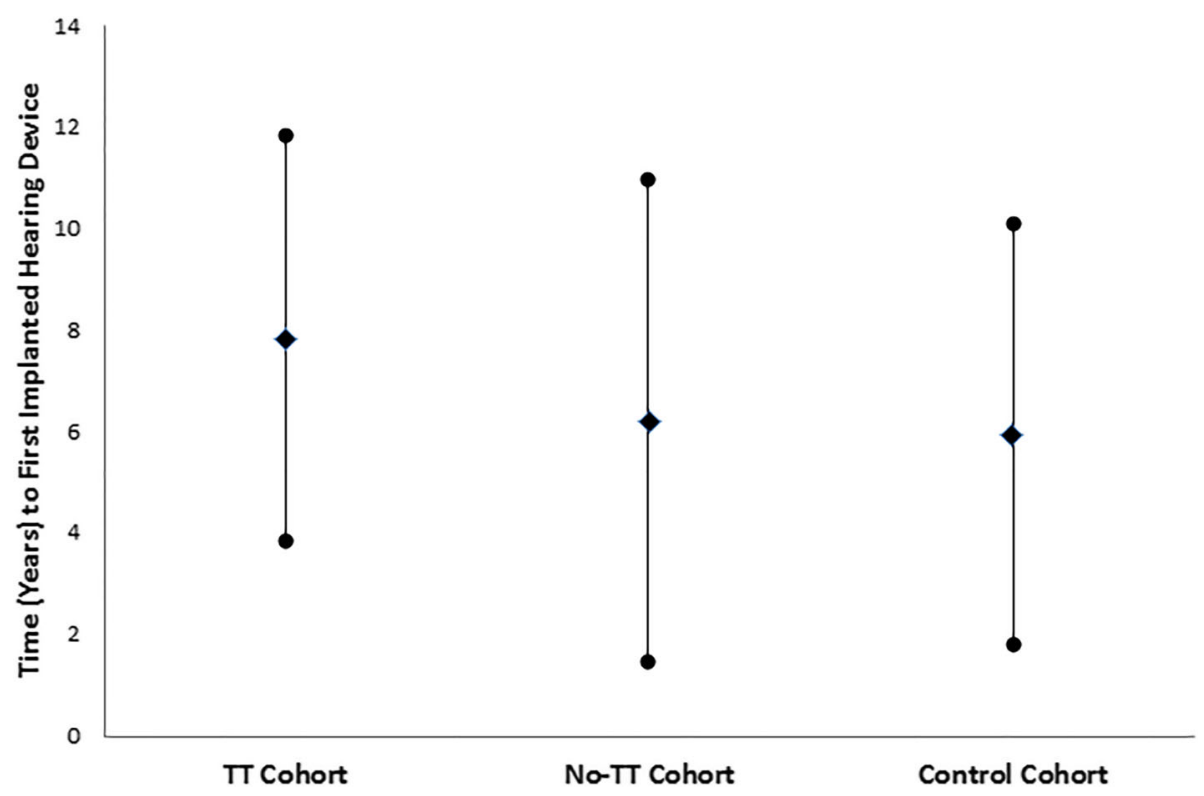

Fig. 2 Time (years) (Mean \pm SD) from index date to first implanted hearing device (bone-conducting hearing aid) in the three cohorts

identified to their school boards upon entry to school (age 4-5). Permanent hearing loss may not be identified until academic performance issues arise or behavioral issues are noted. More thorough audiological testing is requested when these issues are identified, and it is at this time that the diagnosis of permanent hearing loss is made, and personal devices (hearing aids and FM systems) are obtained. This delayed identification of permanent hearing loss could account for the 6 year gap in the studied groups. It is furthermore important to note that the differences between the groups in time to first hearing aid/FM system or time to first implanted hearing device are not statistically significant. This prevents further conclusions from being drawn regarding this data.

The strengths of this study include a large comprehensive population-based design, which includes all patients and all surgeons that perform TT in Ontario. Additionally, the ability to use two control groups and have longterm follow-up greatly enhanced the design. The size of the odds ratios between the groups are notable.

Administrative data has limitations. This study design does not permit an assessment of causation, just an association. Factors that could influence the outcomes such as the indications for surgery, indications for choosing conservative management with serial examinations, secondary smoke exposure, daycare attendance, use of pacifiers, developmental delay, family history of otitis media, audiometric testing results, OHIP diagnostic code data quality, and findings at surgery are not available. Data quality is dependent on accurate coding by the physician and hospital coders. A comparison of administrative data with hospital chart data concluded that major events (surgical procedures, mortality, patient demographics, primary diagnoses) are accurately coded [25]. The diagnostic codes used in constructing the No-TT and Control cohorts were the identical codes that were used by physicians coding middle ear disease in the TT cohort children. Although syndromic children and those with craniofacial abnormalities may be more likely to receive TT than to be managed conservatively, the authors believe that minimal bias would be introduced here, as these patients represent a small minority of those who undergo TT. In a cohort of over 200,000 children who underwent TT, Djurhuus et al. [26] found only $0.6 \%$ had a diagnosis of cleft palate, the most common craniofacial anomaly associated with Eustachian tube dysfunction. Furthermore, our study demonstrated that amongst the patients in each group who obtained a hearing rehabilitative device, only a minority of patients had a diagnosis of cleft palate/lip. Furthermore, in each cohort, over 95\% of the patients with cleft palate/lip did not proceed to a rehabilitative hearing device. As such, we believe the significant difference in rates of rehabilitative hearing devices between the cohorts cannot be adequately explained by a difference in rates of craniofacial abnormalities. Finally, the numbers obtained for FM systems may underestimate the actual incidence, as some schools will purchase FM systems themselves, which would not be captured in ADP data. However, the authors would expect a comparable under-representation of the number of children using FM systems in all three cohorts. 


\section{Conclusions}

This study revealed the actual prevalence of hearing assistive device usage in children in Ontario (healthy, middle ear disease with or without tube placement). While the overall risks are low, recurrent/persistent ear disease and ear tube placement are associated with higher risks. This association requires further evaluation in prospectively-designed studies.

\section{Abbreviations}

ADP: Assistive Devices Program; AOM: Acute Otitis Media; FM: Frequency Modulation; ICES: Institute for Clinical Evaluative Sciences; IKN: ICES Key Number; OHIP: Ontario Health Insurance Plan; OME: Otitis Media with Effusion; OR: Odds Ratio; RPDB: Registered Persons Database; TT: Tympanostomy Tube(s)

\section{Acknowledgements}

1. This study was supported by ICES, which is funded by an annual grant from the Ontario Ministry of Health and Long-Term Care (MOHLTC). The opinions, results and conclusions reported in this paper are those of the authors and are independent from the funding sources. No endorsement by ICES or the Ontario MOHLTC is intended or should be inferred.

2. The dataset was cut at ICES Queen's (Kingston, Ontario). The dataset creation and data analysis was performed at ICES Queen's by Dr. Paul Nguyen.

\section{Authors' contributions}

J.A.B. conceptualized the study, analyzed the data, drafted the initial manuscript, and reviewed and revised the manuscript. B.C. and E.R. conceptualized the study, provided contextualization and analysis of the rehabilitative hearing device data acquisition and interpretation, and reviewed and revised the final manuscript. P.N. conceptualized the study, analyzed the data, and reviewed and revised the manuscript. All authors approved the final manuscript as submitted and agree to be accountable for all aspects of the work.

\section{Funding}

SEAMO New Clinician Scientist Program Research Establishment Funding. The funding body had no role in the design of the study, or the data collection/analysis/interpretation, or in the writing of the manuscript.

\section{Availability of data and materials}

The datasets generated and/or analyzed during the current study are available in the ICES Queen's Data repository, stored at ICES Queen's.

\section{Ethics approval and consent to participate}

This study was approved by the Queen's University Health Sciences \& Affiliated Teaching Hospitals Research Ethics Board (HSREB), project \#6017300.

\section{Consent for publication}

Not applicable

\section{Competing interests}

The authors declare that they have no competing interests.

\section{Author details}

'Department of Otolaryngology, Kingston Health Sciences Centre, Queen's University, Kingston, 144 Brock Street, Kingston, Ontario K7L 5G2, Canada. ${ }^{2}$ ICES Adjunct Scientist ICES Queen's, Queen's University School of Medicine, Kingston, 144 Brock Street, Kingston, Ontario K7L 5G2, Canada. ${ }^{3}$ Department of Speech Language Pathology and Audiology, Hotel Dieu Hospital, Kingston, ON, Canada.
Received: 3 July 2019 Accepted: 12 February 2020

Published online: 18 February 2020

\section{References}

1. Cullen KA, Hall MJ, Golosinskiy A. Ambulatory surgery in the United States, 2006. Natl Health Stat Report. 2009;11:1-25.

2. Nieman $\mathrm{CL}$, Tunkel DE, Boss EF. Do race/ethnicity or socioeconomic status affect why we place ear tubes in children? Int J Pediatr Otorhinolaryngol. 2016:88:98-103.

3. Vlastarakos PV, Nikolopoulos TP, Korres S, Tavoulari E, Tzagaroulakis A, Ferekidis E. Grommets in otitis media with effusion: the most frequent operation in children. But is it associated with significant complications? Eur J Pediatr. 2007;166:385-91.

4. Pichichero ME, Berghash LR, Hengerer AS. Anatomic and audiologic sequelae after tympanostomy tube insertion or prolonged antibiotic therapy for otitis media. Pediatr Infect Dis J. 1989;8:780-7.

5. Stenstrom R, Pless IB, Bernard P. Hearing thresholds and tympanic membrane sequelae in children managed medically or surgically for otitis media with effusion. Arch Pediatr Adolesc Med. 2005;159:1151-6.

6. Tos M, Stangerup SE. Hearing loss in tympanosclerosis caused by grommets. Arch Otolaryngol Head Neck Surg. 1989;115:931-5.

7. Khodaverdi $M$, Jørgensen $G$, Lange $T$, et al. Hearing 25 years after surgical treatment of otitis media with effusion in early childhood. Int J Pediatr Otorhinolaryngol. 2013;77:241-7.

8. Rosenfeld RM, Schwartz SR, Pynnonen MA, Tunkel DE, Hussey HM, Fichera JS, Grimes AM, Hackell JM, Harrison MF, Haskell H, Haynes DS, Kim TW, Lafreniere DC, LeBlanc K, Mackey WL, Netterville JL, Pipan ME, Raol NP, Schellhase KG. Clinical practice guideline: Tympanostomy tubes in children. Otolaryngol Head Neck Surg. 2013;149:S1-35.

9. Browning GG, Rovers MM, Williamson I, Lous J, Burton MJ. Grommets (ventilation tubes) for hearing loss associated with otitis media with effusion in children. Cochrane Database Syst Rev. 2010;10:CD001801.

10. Hellström S, Groth A, Jörgensen F, Pettersson A, Ryding M, Uhlén I, Boström KB. Ventilation tube treatment: a systematic review of the literature. Otolaryngol Head Neck Surg. 2011:145:383-95.

11. Wallace IF, Berkman ND, Lohr KN, Harrison MF, Kimple AJ, Steiner MJ. Surgical treatments for otitis media with effusion: a systematic review. Pediatr. 2014;133:296-311.

12. Armstrong BW, Armstrong RB. Tympanostomy tubes, their use, abuse, and cost-benefit ratio. Laryngoscope. 1979;89:443-9.

13. Le $\mathrm{CT}$, Freeman DW, Fireman BH. Evaluation of ventilating tubes and myringotomy in the treatment of recurrent or persistent otitis media. Pediatr Infect Dis J. 1991;10:2-11.

14. Swedish Council on Health Technology Assessment. Tympanostomy Tube Insertion for Otitis Media in Children: A Systematic Review [Internet]. Stockholm: Swedish Council on Health Technology Assessment (SBU); 2008. SBU Yellow Report No 189

15. Kujala T, Alho OP, Luotonen J, Kristo A, Uhari M, Renko M, Kontiokari T, Pokka T, Koivunen P. Tympanostomy with and without adenoidectomy for the prevention of recurrences of acute otitis media: a randomized controlled trial. Pediatr Infect Dis J. 2012;31:565-9.

16. Steele D, Adam GP, Di M, Halladay C, Pan I, Coppersmith N, Balk EM, Trikalinos TA. Tympanostomy Tubes in Children With Otitis Media [Internet]. Rockville (MD): Agency for Healthcare Research and Quality (US); 2017. Report No.: 17-EHCO03-EF

17. Skinner DW, Lesser TH, Richards SH. A 15 year follow-up of a controlled trial of the use of grommets in glue ear. Clin Otolaryngol Allied Sci. 1988;13:341-6.

18. Maw AR, Bawden R. Tympanic membrane atrophy, scarring, atelectasis and attic retraction in persistent, untreated otitis media with effusion and following ventilation tube insertion. Int J Pediatr Otorhinolaryngol. 1994;30: 189-204.

19. O'Niel MB, Cassidy LD, Link TR, Kerschner JE. Tracking tympanostomy tube outcomes in pediatric patients with otitis media using an electronic database. Int J Pediatr Otorhinolaryngol. 2015;79:1275-8.

20. Paradise JL, Campbell TF, Dollaghan CA, et al. Developmental outcomes after early or delayed insertion of tympanostomy tubes. $\mathrm{N}$ Engl J Med. 2005:353:576-86

21. Paradise $J \mathrm{~L}$, Feldman HM, Campbell TF, et al. Tympanostomy tubes and developmental outcomes at 9 to 11 years of age. N Engl J Med. 2007;356: 248-61. 
22. Beyea JA, Paradis J, Nguyen P, Hall SF. Association of Tympanostomy Tubes with Future Risk of advanced ear surgery-a population study. Otol Neurotol Otol Neurotol. 2019:40:478-84.

23. Brown MJ, Richards SH, Ambegaokar AG. Grommets and glue ear: a fiveyear follow up of a controlled trial. J R Soc Med. 1978;71:353-6.

24. Kay DJ, Nelson M, Rosenfeld RM. Meta-analysis of tympanostomy tube sequelae. Otolaryngol Head Neck Surg. 2001;124:374-80.

25. Hawker GA, Coyte PC, Wright JG, Paul JE, Bombardier C. Accuracy of administrative data for assessing outcomes after knee replacement surgery. J Clin Epidemiol. 1997;50:265-73.

26. Djurhuus BD, Christensen K, Skytthe A, Faber CE. The impact of ventilation tubes in otitis media on the risk of cholesteatoma on a national level. Int $J$ Pediatr Otorhinolaryngol. 2015;79:605-9.

\section{Publisher's Note}

Springer Nature remains neutral with regard to jurisdictional claims in published maps and institutional affiliations.

Ready to submit your research? Choose BMC and benefit from:

- fast, convenient online submission

- thorough peer review by experienced researchers in your field

- rapid publication on acceptance

- support for research data, including large and complex data types

- gold Open Access which fosters wider collaboration and increased citations

- maximum visibility for your research: over $100 \mathrm{M}$ website views per year

At BMC, research is always in progress.

Learn more biomedcentral.com/submissions 